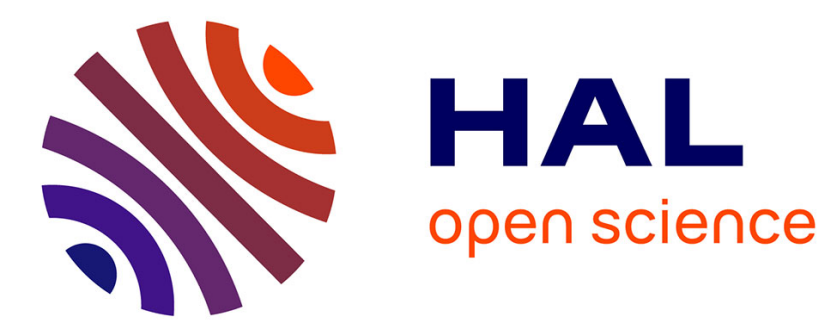

\title{
Spatial distributions of plasma parameters in conventional magnetron discharges in presence of nanoparticles
}

Alebia Chami, Cécile Arnas

\section{- To cite this version:}

Alebia Chami, Cécile Arnas. Spatial distributions of plasma parameters in conventional magnetron discharges in presence of nanoparticles. Journal of Plasma Physics, 2020. hal-02954792

\author{
HAL Id: hal-02954792 \\ https://hal.science/hal-02954792
}

Submitted on 1 Oct 2020

HAL is a multi-disciplinary open access archive for the deposit and dissemination of scientific research documents, whether they are published or not. The documents may come from teaching and research institutions in France or abroad, or from public or private research centers.
L'archive ouverte pluridisciplinaire HAL, est destinée au dépôt et à la diffusion de documents scientifiques de niveau recherche, publiés ou non, émanant des établissements d'enseignement et de recherche français ou étrangers, des laboratoires publics ou privés. 


\title{
${ }_{1}$ Spatial distributions of plasma parameters in ${ }_{2}$ conventional magnetron discharges in presence ${ }_{3}$ of nanoparticles
}

\author{
${ }_{4}$ A. Chami ${ }^{1}$ and C. Arnas ${ }^{1}{ }^{\dagger}$ \\ $5{ }^{1}$ Aix-Marseille université, CNRS, PIIM, 13397 Marseille, France \\ 6 (Received 26 May 2020; revised 31 July 2020; accepted 31 July 2020)
}

\begin{abstract}
7 Two-dimensional spatial measurements of magnetic field and plasma parameters have 8 been performed in conventional magnetron DC discharges during the formation of 9 metallic nanoparticles. Correlations between the electron density and temperature 10 distributions, and the magnetic field geometry and strength have been established. A sharp 11 increase of the plasma potential is found on the edge of the last magnetic arch followed 12 by a decrease towards the anode plate and edges. It is shown that the spatial variation of 13 the plasma potential is at the origin of a potential well that can trap negatively charged 14 nanoparticles.
\end{abstract}

15 Key words: electric discharges, dusty plasmas, plasma diagnostics

$\dagger$ Email address for correspondence: cecile.arnas@univ-amu.fr

\section{1. Introduction}

17 Many studies have explored the mechanisms of nanoparticle (NP) formation in 18 low-temperature plasmas for various applications extending from electronics (Grieve, 19 Mulvaney \& Grieser 2000), optics (Kelly et al. 2003), magnetism (Wei et al. 2009) 20 and catalysis (Cuenya 2010) to biology or medicine since nanoscale materials present 21 enhanced properties compared to those of bulk materials (Chauduri \& Paria 2012). Various 22 ionization sources can be used in this domain such as radio-frequency discharges (Couedel 23 et al. 2010), microwave electron cyclotron resonance discharges (Ouaras et al. 2015; Rojo 24 et al. 2019) and DC discharges (Kishor Kumar, Couedel \& Arnas 2014; Michau, Hassouni 25 \& Arnas 2017) as well as magnetron sputtering discharges in a gas-aggregation system 26 (MS-GAS) (Kashtanov, Sirnov \& Hippler 2007; Hartmann et al. 2012; Caillard et al. 2015) 27 and conventional magnetron discharges that we use for basic studies on NP formation 28 (Arnas et al. 2019). For a given plasma source, NP formation depends strongly on the 29 discharge conditions (geometry, magnetic field configuration if any, discharge current 30 and voltage, gas pressure and temperature). These conditions also determine the plasma 31 parameters at the origin of the charging, heating and transport of the NPs in the plasma 32 as well as their internal features such as morphology, size and crystallinity from which 33 potential applications can be considered. Plasma parameter measurements are therefore of 34 prime interest.

35 Few measurements have been reported on plasma parameters for the conditions of 36 magnetron discharges operating at rather high pressure for NP production. Langmuir 37 probes (LPs) were used in some cases in MS-GAS in a single position under the 38 racetrack (Koten et al. 2016), and recently in radial and axial directions of MS-GAS, when 39 the cathode is in a partially oxidized state (Kousal et al. 2017). Conversely, numerous 40 measurements and modelling were performed to describe magnetron discharges operating 41 at low pressure ( $<0.05 \mathrm{mbar}$ ) (Field, Dew \& Burrell 2002) in order to improve deposition 42 rates and specific coating qualities (Depla \& Leroy 2012). For instance, a complete 43 study of the spatial variations of plasma potential was conducted to find the electron $44 \mathrm{E} \times \mathrm{B}$ drift velocities near the cathode and in the plasma volume (Bradley, Thompson $45 \&$ Aranda Gonzalvo 2001). A complete three-dimensional map of the plasma parameters 
46 was established pointing out the racetrack region where the most intense ion bombardment 47 takes place (Palmero et al. 2004).

48 In this article, we present measurements in two spatial dimensions of the magnetic field 49 and plasma parameters of conventional DC magnetron discharges during the formation 50 of NPs. The latter are synthesized from the sputtering of the cathode in tungsten at an 51 argon pressure of 0.3 mbar. Measurements of the magnetic field were carried out with a 52 Hall probe without plasma and a LP was used to find the plasma parameters. Correlations 53 between the magnetic field strength and lines, and the spatial variations of the electron 54 density and temperature have been established. A sharp increase of the plasma potential 55 was found around the last magnetic arch allowing the deduction of the potential energy of 56 a negatively charged NP. A potential well was found and its role is discussed.

\section{Experimental set-up and diagnostic procedures}

58 The experimental set-up was already presented (Arnas et al. 2019) and is schematized 59 in figure 1. Experiments are conducted in a stainless steel cylinder of $40 \mathrm{~cm}$ in length 60 and $30 \mathrm{~cm}$ in diameter. The ionization source is an unbalanced planar magnetron system 61 (mcse-ROBEKO). The cathode is a tungsten disc ( $99.95 \%$ purity) of $7.6 \mathrm{~cm}$ in diameter 62 and $0.3 \mathrm{~cm}$ in width. A grounded guard ring of $2 \mathrm{~cm}$ in width and $1 \mathrm{~cm}$ in height $(\sim 7.4 \mathrm{~cm}$ 63 inner diameter) is set under the cathode at a distance of $\sim 0.2 \mathrm{~cm}$. A grounded stainless 64 steel disc of $15 \mathrm{~cm}$ in diameter (anode plate) is placed parallel to the cathode at $10 \mathrm{~cm}$. Two 65 half-glass cylinders, $12 \mathrm{~cm}$ in diameter and $10 \mathrm{~cm}$ long, are placed around this magnetron 66 system. In order to insert a LP in the plasma, the half-glass cylinders are separated by two 67 diametrically opposed gaps of $\sim 1.5 \mathrm{~cm}$.

68 Discharges are produced in argon at $0.3 \mathrm{mbar}$ and $5 \mathrm{sccm}$ (standard cubic centimetres 69 per minute) flow rate. The discharge current is maintained constant at $0.3 \mathrm{~A}$ using a 70 DC current-regulated power supply (Glassman HV, $1 \mathrm{~A}-1 \mathrm{kV}$ ) and the discharge voltage 71 self-adjusts to approximately $-200 \mathrm{~V}$. The formation of NPs and then their sampling are 72 carried out on stainless steel polished substrates, which are pushed one after the other 73 under a hole drilled in the centre of the anode disc. The description of their formation in 74 such discharge conditions and geometry as well as their structural properties were already 75 reported in (Arnas et al 2019) and will not be discussed in this article. $76 \mathrm{~A}$ Hall probe was used to measure the magnitude of the magnetic field when the 77 discharge was not operational. For this, a small gallium arsenide semiconductor plate 78 of $0.1 \mathrm{~cm} \times 0.1 \mathrm{~cm}$ embedded in a thin long resin stripe linked to a gaussmeter

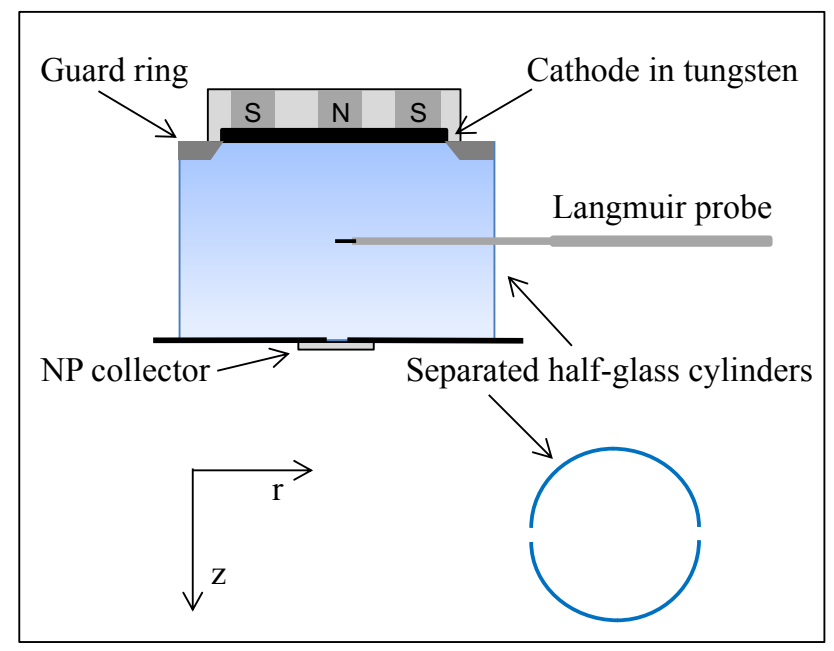

FIGURE 1. Experimental set-up. The lower-right part represents the top view of the two half-glass cylinders. They are slightly opened to allow introduction of a LP. This set-up is inside a stainless steel cylinder 
79 (GM08-HIRST) was used. This sensor was displaced radially every $0.2 \mathrm{~cm}$ from $\mathrm{r}=-5$ 80 to $\mathrm{r}=5 \mathrm{~cm}, 0 \mathrm{~cm}$ being the centre of the cathode. These measurements were repeated 81 vertically every $0.5 \mathrm{~cm}$ from $0.4 \mathrm{~cm}$ of the copper baking plate where the cathode plate is 82 fixed to the anode plate. Measurements were taken directly with the calibrated gaussmeter. 83 A homemade cylindrical LP consisting of a tungsten wire $0.0125 \mathrm{~cm}$ in diameter and $84 \sim 1 \mathrm{~cm}$ in length was used to measure the plasma parameters. The probe axis was displaced 85 radially, every centimetre from $r=-2$ to $r=6 \mathrm{~cm}$ (position of the glass tubes). The 86 same radial measurements were made by moving the probe vertically every centimetre 87 from $\mathrm{z}=2$ to $\mathrm{z}=9 \mathrm{~cm}$ (or $1 \mathrm{~cm}$ above the anode plate). To avoid the LP contamination, 88 the plasma duration was limited to the time necessary for probe cleaning by electron 89 bombardment (several seconds, several times), and then to the time necessary to acquire 90 three LP characteristics in $\sim 15 \mathrm{~s}$. Several series of characteristics were obtained for a 91 given $\mathrm{z}$ and the LP was changed in every $\mathrm{z}$ position. A commercial driver (Princeton 92 Instruments) was used for LP cleaning and current-bias (I-V) acquisition every $\delta \mathrm{V}$ 93 200 $\mathrm{mV}$. The I-V data were then collected with a 12-bit A/D convertor (National 94 Instruments). Homemade programs using the software Matlab allowed establishing the 95 spatial magnetic field strength and lines as well as the plasma parameters.

\section{Spatial distribution of the magnetic field}

97 Construction of the magnetic field lines and values ( $\mathrm{B}$ in gauss) in colour are shown in 98 figure 2(a). The cathode is represented in black at $\mathrm{z}=0-0.3 \mathrm{~cm}$ as well as the guard ring 99 under each cathode side. The magnetron is unbalanced: magnetic field arches are present 100 over a distance of $\mathrm{z} \sim 3.8 \mathrm{~cm}$ and a part of the magnetic field lines in the cathode centre 101 and peripheries is directed towards the anode plate. Red lines give some contour plots of 102 the magnetic field strength. Figure 2(b) shows the decrease of the magnetic field from the 103 cathode, axially (for $\mathrm{r}=0 \mathrm{~cm}$ ) as well as under the position of the so-called 'racetrack' $104(\mathrm{r}=2 \mathrm{~cm})$ where the sputtering is maximum (under the magnetic field lines parallel to 105 the cathode) and under the edge of the cathode $(\mathrm{r}=4 \mathrm{~cm})$. At the cathode surface centre, $106 \mathrm{~B} \sim 860 \mathrm{G}$. The magnetic null point is at $\mathrm{z} \sim 3.8 \mathrm{~cm}$. Its position in the colour map is in
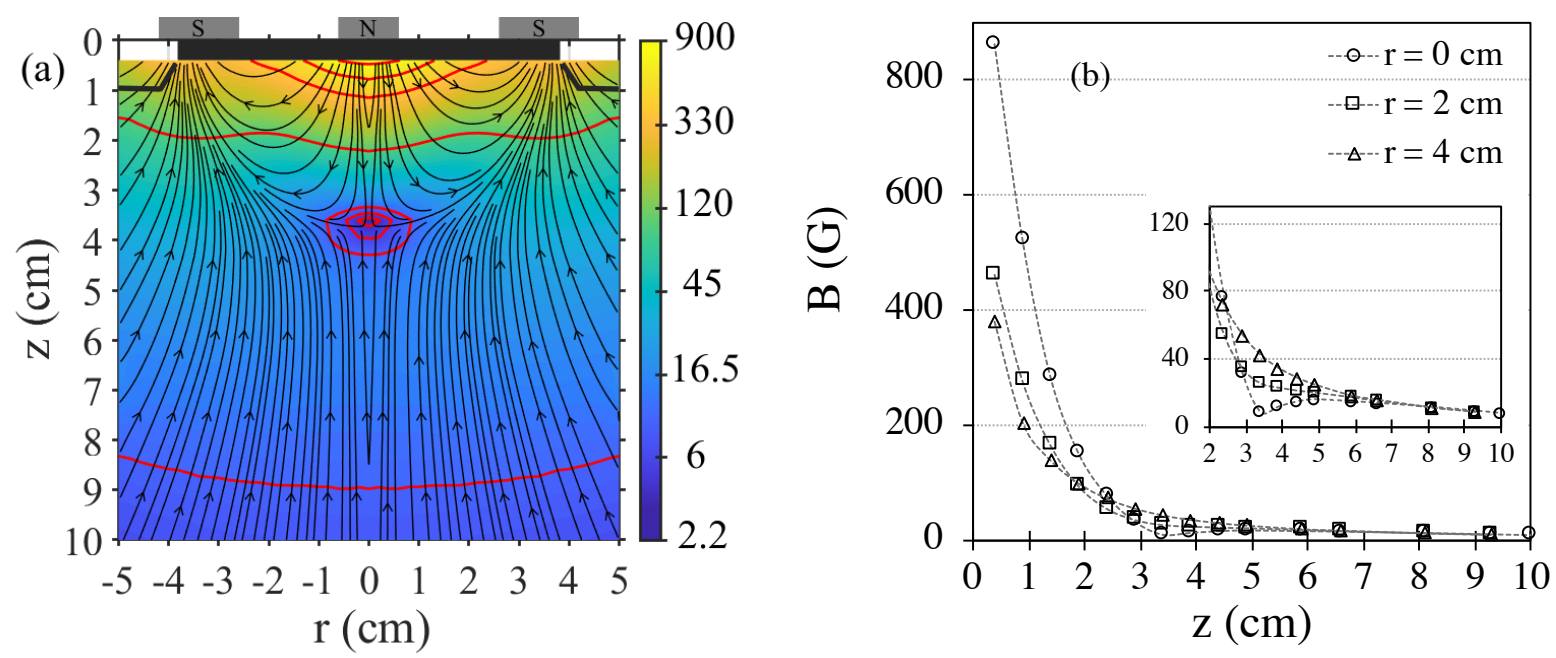

Figure 2. (a) Magnetic field measurements from the cathode $(\mathrm{z}=0.3 \mathrm{~cm})$ to the grounded anode plate $(\mathrm{z}=10$ $\mathrm{cm})$. Magnetic field line directions are represented by arrows; colours give the strength and some contour lines are in red. (b) Decrease of the magnetic field axially $(\mathrm{r}=0 \mathrm{~cm})$, under the racetrack $(\mathrm{r}=2 \mathrm{~cm})$ and under the cathode edge $(r=3.8 \mathrm{~cm})$. Inset: magnified view from $\mathrm{z}=2 \mathrm{~cm}$ where LP measurements were performed. 
107 the centre of the closed contour lines. The magnified view in the inset of figure 2(b) also 108 shows this position on the plasma axis. Moreover, the inset provides the detail of $\mathrm{B}$ from $109 \mathrm{z}=2 \mathrm{~cm}$ where LP measurements began to $10 \mathrm{~cm}$. At $\mathrm{z}=2 \mathrm{~cm}$, the maximum of $\mathrm{B}$ is $110 \sim 130 \mathrm{G}$. For $\mathrm{z}>6 \mathrm{~cm}$, whatever the radial position, $\mathrm{B}<20 \mathrm{G}$ and at $\mathrm{z}=9-10 \mathrm{~cm}$, $111 \mathrm{~B} \sim 8 \mathrm{G}$.

\section{4. Spatial distribution of plasma parameters}

113 Earlier studies have shown that the I-V characteristic of a cylindrical probe is not 114 perturbed by magnetic fields if its axis is perpendicular to the magnetic field lines and if the 115 probe radius $r_{p}$ is small compared to the Larmor radius $r_{L}$ of the charged particles. Hence, 116 when $\beta=r_{p} / r_{L} \ll 1$, the magnetic field influence is neglected (Kolpakova, Kudrna \& 117 Tichy 2013). In our conditions, this condition was post-checked by an evaluation of $118 \mathrm{r}_{\mathrm{L}} \sim 400 \mu \mathrm{m}$ at $\mathrm{z}=2 \mathrm{~cm}$ in comparison with $\mathrm{r}_{\mathrm{p}}=62.5 \mu \mathrm{m}$ and confirmed for $\mathrm{z}>2 \mathrm{~cm}$, a 119 region of a strong magnetic field decrease.

120 Assuming in a first approximation that only Ar atoms are ionized, the I-V characteristics 121 of the LP have shown that the electron population is quasi-Maxwellian in the plasma plane, $122 \mathrm{r}-\mathrm{z}$. The plasma potential $\mathrm{V}_{\mathrm{p}}$ was found from the first derivative or the inflexion point of 123 the I-V curve after subtracting the saturation ion current of the total probe current. The 124 electron density and temperature $\left(n_{e}\right.$ and $T_{e}$, respectively) were found classically: $n_{e}$ from 125 the expression of the electron saturation current of a cylindrical LP in $V_{p}$, and $T_{e}$ by fitting 126 the I-V characteristic curve by an exponential function from the probe floating potential 127 to $\mathrm{V}_{\mathrm{p}}$.

128 Figures 3(a) and 3(b) show $n_{e}$ and $T_{e}$ variations, respectively, from $r=-2$ to $r=6 \mathrm{~cm}$.

129 Measurements from $\mathrm{r}=-3$ to $-6 \mathrm{~cm}$ are not reported. They were perturbed by shadowing 130 effects of the insulating tube part of the LP which was translated horizontally from a 131 single lateral window of the vacuum chamber. However, measurements from $r=0$ to $132-2 \mathrm{~cm}$ show that the axial symmetry of the magnetron system is fulfilled. For greater 133 clarity, measurement error bars are only shown for data obtained for $\mathrm{z}=9 \mathrm{~cm}$ of figure 3(a) 134 and for $z=8 \mathrm{~cm}$ of figure 3(b). In the latter case, the data symbol was reduced to show 135 better the error bars.

136 Two regions are revealed in figure 3 (a). In the region located before the null point, from $137 \mathrm{Z}=2$ to $\sim 4 \mathrm{~cm}$, the maximum of $n_{\mathrm{e}}$ is inside the magnetic arches. Parameter $n_{e}$ decreases 138 towards the discharge axis and to lower values towards the half-glass cylinder position. 139 The maximum at $\mathrm{z}=2 \mathrm{~cm}$ is $\sim 1.5 \times 10^{17} \mathrm{~m}^{-3}$. From the null point position to the anode 140 plate, $\mathrm{n}_{\mathrm{e}}$ is maximum on the discharge axis and decreases axially and radially.

(a)

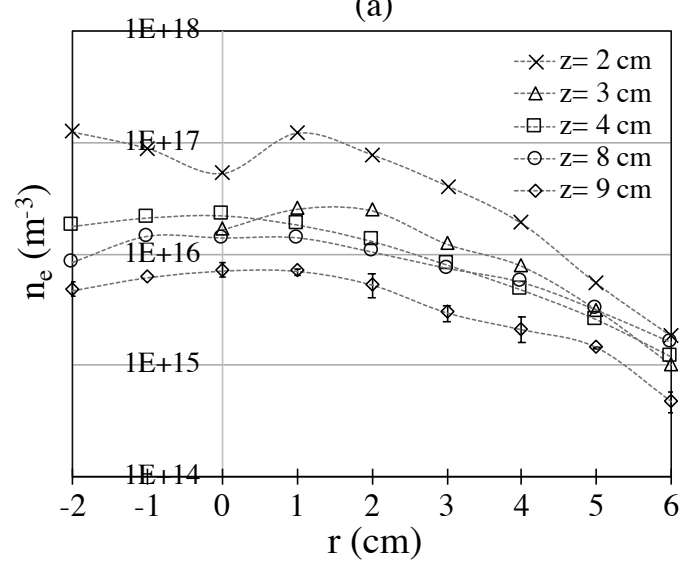

(b)

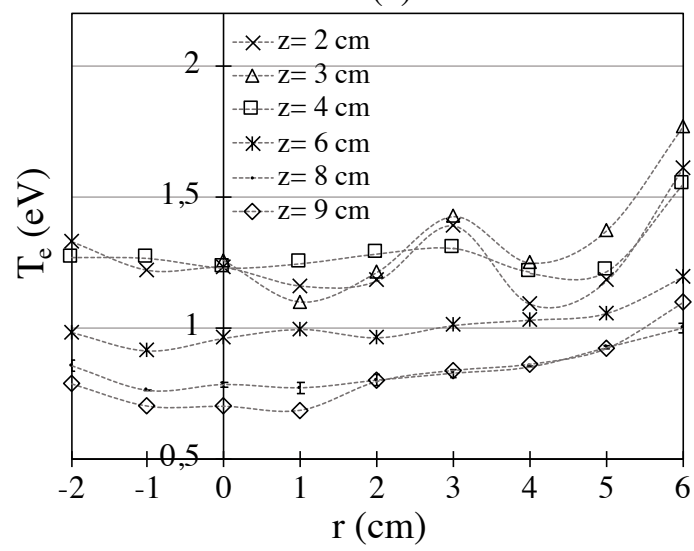

F I G U R E 3. (a) Electron density and (b) temperature measurements from $\mathrm{r}=-2$ to $0 \mathrm{~cm}$ (axial position) and $\mathrm{r}=0$ to $6 \mathrm{~cm}$ (half-glass tube position), for various distances $\mathrm{z}$ to the cathode. Symmetric measurements with respect to the discharge axis were stopped at $r=-2 \mathrm{~cm}$ because of LP shadowing effects. 
141 Figure 3(b) shows the distributions of $T_{e}$. There is a minimum of $T_{e}$ when $n_{e}$ is 142 maximum under the magnetic arches. A second minimum appears around $\mathrm{r} \sim 4 \mathrm{~cm}$, the 143 position of the guard ring of $1 \mathrm{~cm}$ in height (see figure $2 \mathrm{a}$ ). The maximum of $\mathrm{T}_{\mathrm{e}} \sim 1.8 \mathrm{eV}$ 144 is reached at the plasma edge, in between the half-glass cylinders. Beyond the magnetic 145 arches, $T_{e}$ progressively decreases vertically as $n_{e}$ does. The lower value, $T_{e}=0.75 \mathrm{eV}$, is 146 obtained above the anode plate at $\mathrm{z}=9 \mathrm{~cm}$.

147 Figures 4(a)-4(c) provide, in the $r-z$ plane, the variations in colour of $n_{e}, T_{e}$ and $148 \mathrm{~V}_{\mathrm{p}}$, respectively. The magnetic field lines are added in figure 4(a). They highlight the 149 correlation existing between the position of the maximum plasma density and the position 150 of the magnetic arches. They are not added in the colour map of $\mathrm{T}_{\mathrm{e}}$ for more clarity, but 151 it appears that in the arch regions, $\mathrm{T}_{\mathrm{e}}$ has a minimum where the density is at maximum 152 and then increases when the density decreases. The superimposition of magnetic field 153 lines in figure 4(c) shows that $\mathrm{V}_{\mathrm{p}}$ has negative values inside the magnetic arches, reaching $154-0.3 \mathrm{eV}$. A sharp increase is observed in the edge of the last magnetic arch. The largest 155 positive values are under the guard ring and more generally in a central band, parallel to 156 the cathode, from $\mathrm{z} \sim 4$ to $\sim 7 \mathrm{~cm}$. This is also shown in figure 5 (a) versus $\mathrm{z}$ from $\mathrm{r}=0$ to $1575 \mathrm{~cm}$. This spatial distribution of $\mathrm{V}_{\mathrm{p}}$ is at the origin of a potential well for NPs as presented 158 in the next section.
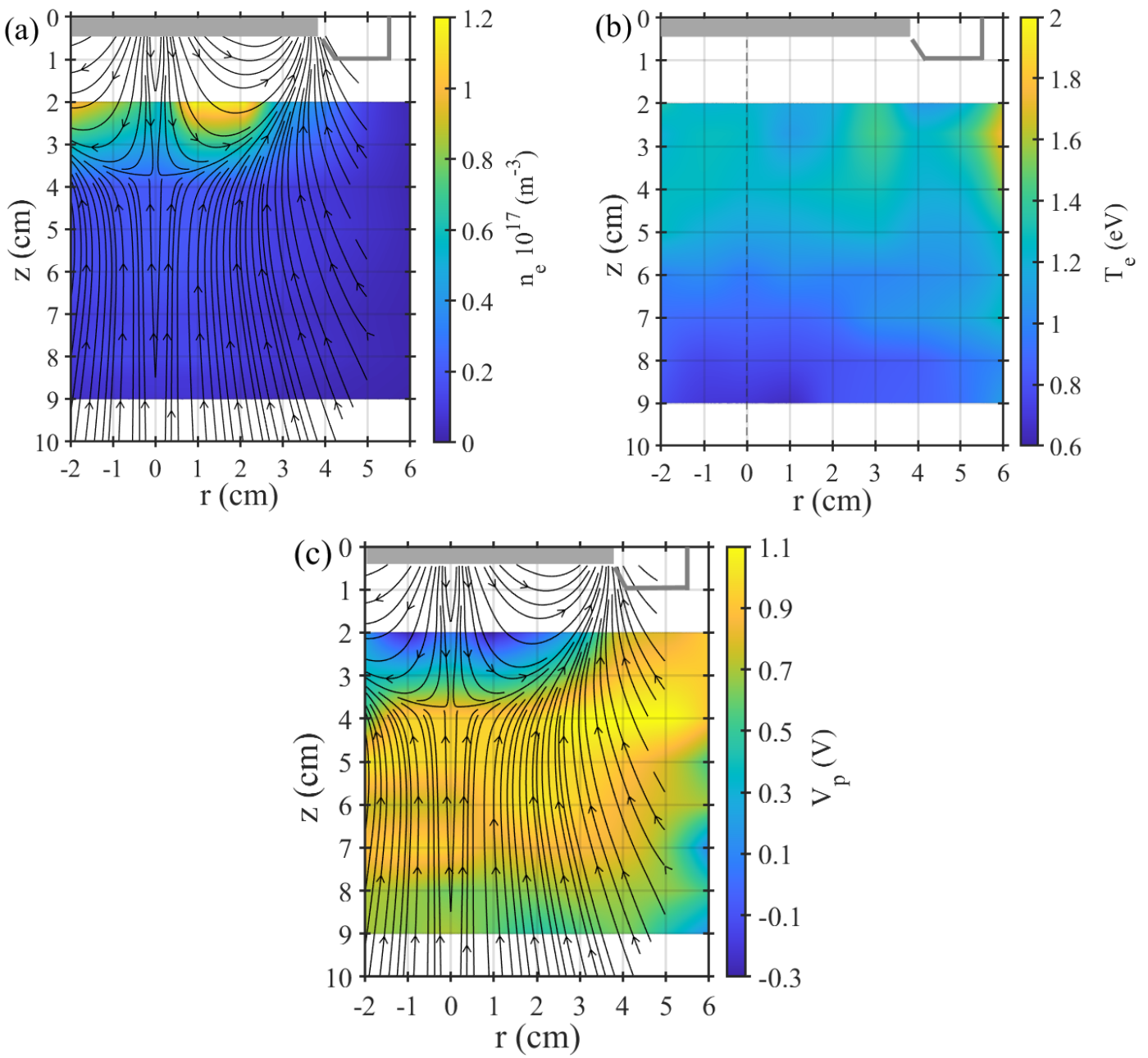

FIGURE 4. Spatial distribution in colour in the (r, z) plane of (a) the electron density, (b) the electron temperature and (c) the plasma potential. Magnetic field lines are superimposed on the electron density and the plasma potential maps. 


\section{5. Equilibrium position of a nanoparticle}

160 It has been shown (Arnas et al. 2019) that the mean size of NPs synthesized from 161 tungsten sputtering in magnetron discharges similar to those described above is around $16220 \mathrm{~nm}$ after a $15 \mathrm{~s}$ discharge. The charging of an isolated dust particle is calculated 163 classically using the orbital motion limited model where it is supposed that the ions and 164 electrons have an orbital trajectory around the particle (Bernstein \& Rabinowitz 1959). 165 The equality between the electron and the ion flux at the NP surface provides the NP 166 floating potential $\Phi$ with respect to the plasma potential, from which one can deduce the $167 \mathrm{NP}$ negative charge. In the plasma volume, the expression of the ion flux is

$168 \quad \mathrm{I}_{\mathrm{i}}(\phi)=\frac{\mathrm{S}}{4} \mathrm{n}_{0} v_{\mathrm{i}}\left(1-\frac{2 e \phi}{m_{i} v_{i}^{2}}\right)$

169 where $\mathrm{S}$ is the NP surface, $\mathrm{n}_{0}$ the plasma density and $\mathrm{v}_{\mathrm{i}}$ the ion thermal velocity. The 170 expression of the electron flux is

$171 \quad \mathrm{l}_{\mathrm{e}}(\phi)=\frac{\mathrm{S}}{4} \mathrm{n}_{\mathrm{O}} v_{\mathrm{e}} \exp \left(\frac{e \phi}{k_{B} T_{e}}\right)$,

172 were $V_{e}$ is the electron thermal velocity. The negative charge is given by $Q_{d}=4 \pi \varepsilon_{0} r_{d} V_{\text {flot }}$, 173 where $r_{d}$ and $V_{\text {flot }}$ are the NP radius and floating potential, respectively. Figure 5(b) shows 174 the variations of $Q_{d}$ in electron units versus $z$, for $r=0$ to $5 \mathrm{~cm}$. The maximum charge is 175 reached in the cathode side for $z=3$ to $\sim 4 \mathrm{~cm}$. Charge modulations are present along $\mathrm{z}$ 176 but on average, the charge decreases from $\mathrm{z}=4$ to $9 \mathrm{~cm}$.

177 The potential energy of an isolated dust particle in every $(\mathrm{r}, \mathrm{z})$ position is due to the 178 contributions of the electrostatic and gravitational forces:

$179 \mathrm{E}_{\mathrm{tot}}=\mathrm{Q}_{\mathrm{d}} \mathrm{V}_{\mathrm{p}}-\mathrm{m}_{\mathrm{d}} \mathrm{g}\left(\mathrm{z}_{0}-\mathrm{z}\right)$,

180 where $m_{d}$ is the NP mass, $g$ the gravity intensity and $z_{0}=10 \mathrm{~cm}$ is the distance between 181 the electrodes. The potential energy $\mathrm{m}_{\mathrm{d}} \mathrm{g}\left(\mathrm{z}_{0}-\mathrm{z}\right)$ is at least two orders of magnitude lower

(a)

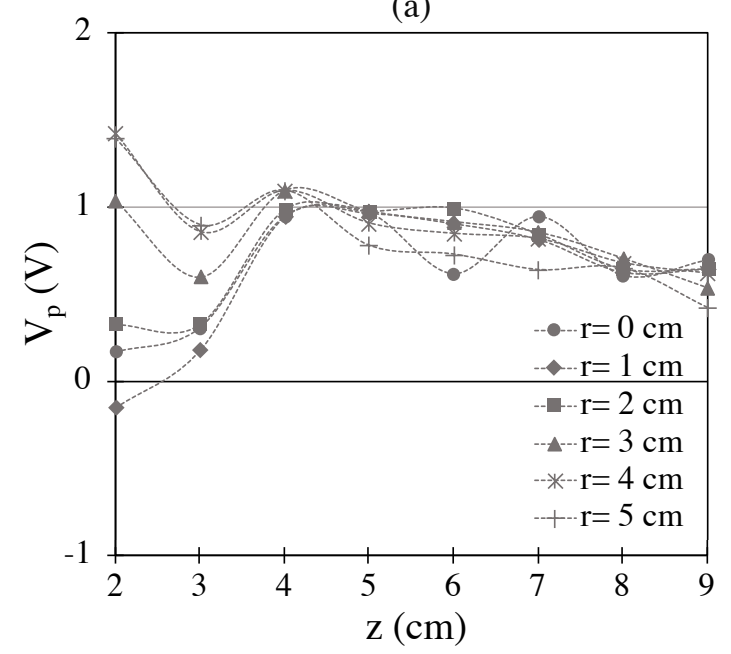

(b)

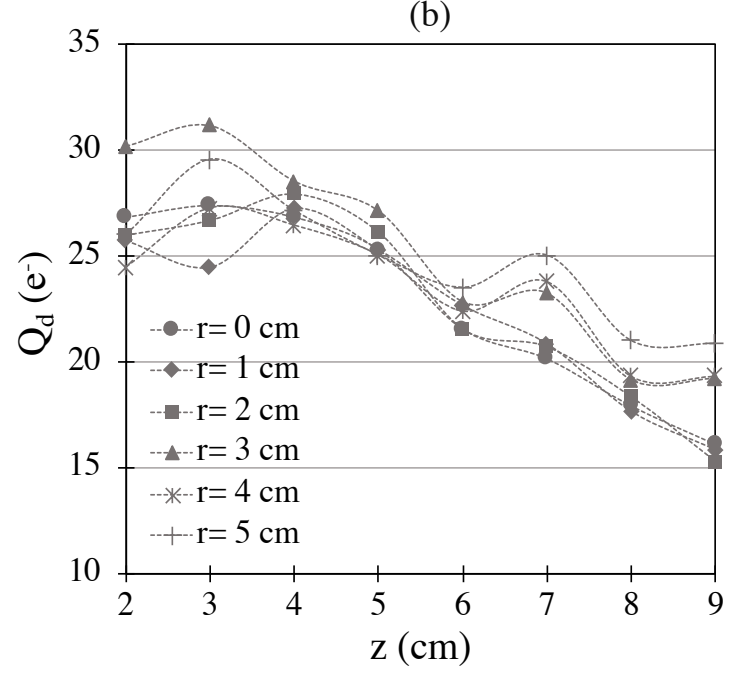


(c)

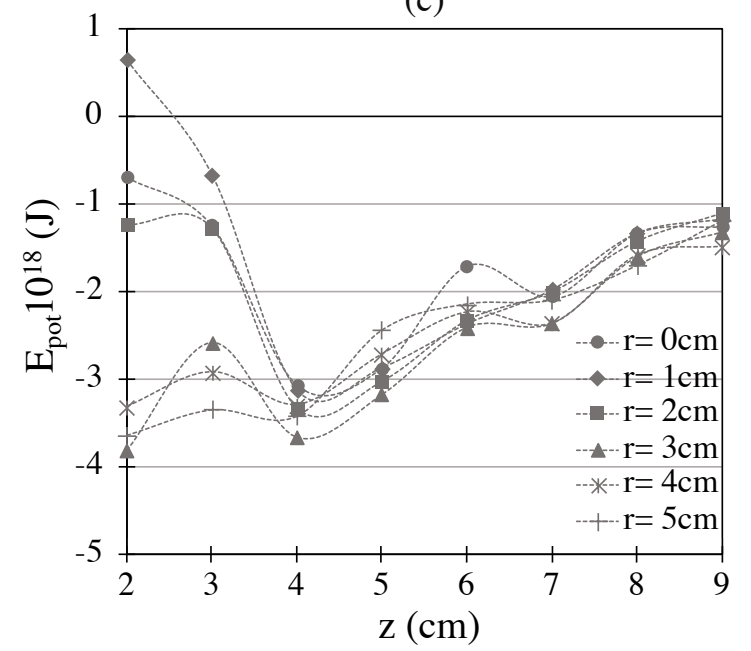

FIGURE 5. Variations versus the distance $\mathrm{z}$ for $\mathrm{r}=0$ to $5 \mathrm{~cm}$ of (a) the plasma potential, (b) the charge in electron units of an isolated NP of $20 \mathrm{~nm}$ in size and (c) the potential energy of the NP deduced from the charge and the plasma potential distributions.

182 than $\mathrm{Q}_{\mathrm{d}} \mathrm{V}_{\mathrm{p}}$, everywhere. Figure 5(c) shows the variations of $\mathrm{E}_{\text {tot }}$. A potential well is clearly 183 evidenced at $\mathrm{z}=4 \mathrm{~cm}$ for $\mathrm{r}=0$ to $2 \mathrm{~cm}$, and likely to $\mathrm{r}=3 \mathrm{~cm}$. From $\mathrm{r}=4$ to $5 \mathrm{~cm}$, $184 \mathrm{E}_{\text {tot }}$ presents modulations along $\mathrm{z}$. The corresponding absolute values decrease on average 185 from $\mathrm{z}=2$ to $\mathrm{z}=9 \mathrm{~cm}$.

\section{6. Discussion}

187 In the discharge axis and close to the cathode, the magnetic field has the largest values. It 188 is directed perpendicularly to the cathode in contrast to the etch region were the magnetic 189 field is parallel to the cathode. Hence, electrons move easily axially, being impeded from 190 moving in a lateral direction. As a consequence, the plasma density is lower along the 191 plasma axis and in all regions where the magnetic field lines are normal to the cathode. 192 Moreover, when the magnetic field normal to the cathode drops, the electron gyro-radius 193 increases and transport towards the lateral wall is also favoured, in particular from $194 \mathrm{z}>4 \mathrm{~cm}$. Meanwhile, electrons trapped in the high-field regions parallel to the cathode 195 produce more ionization collisions.

196 Modelling at low pressure (Bogaerts, Kolev \& Buyle 2008) has shown that for the 197 discharge sustainment carried out by secondary electrons ejected from the cathode, the 198 maximum ionization rate is located under the racetrack, in the sheath and also for a 199 significant amount in the cathode pre-sheath. It was shown that the latter can have widths 200 of several centimetres in magnetrons operating with strong magnetic field (Shidoji \& 201 Makabe 2003) and low pressure (Bradley et al. 2001; Shidoji \& Makabe 2003). In our 202 experimental conditions, the pre-sheath extends over $\sim 2 \mathrm{~cm}$ from the cathode region 203 where $V_{p}$ is still negative. In the pre-sheath region to $\mathrm{z} \sim 4 \mathrm{~cm}, \mathrm{~T}_{\mathrm{e}}$ and $\mathrm{n}_{\mathrm{e}}$ are inversely 204 proportional. This answers to a general trend in plasmas where in order to sustain the 205 discharge, the electron temperature increases when the electron density decreases, in 206 particular when there is diffusion towards the wall. From $\mathrm{z}>4 \mathrm{~cm}$ towards the anode 207 plate position, $T_{\mathrm{e}}$ and $\mathrm{n}_{\mathrm{e}}$ decrease. Moreover, $\mathrm{T}_{\mathrm{e}}$ decreases to values $\leq 1 \mathrm{eV}$ indicating that 208 electron ionization can no longer take place in this region.

209 The cooling of $\mathrm{T}_{\mathrm{e}}$ in the presence of metallic atoms of lower ionization potential than the 210 buffer gas has already been reported (Hopwood \& Qian 1995; Sigurjonsson et al. 2009). 211 The $\mathrm{W}$ ionization energy is $7.86 \mathrm{eV}$ against $15.76 \mathrm{eV}$ for Ar. We assume that $\mathrm{W}$ ionization 212 is performed for $\mathrm{z}<2 \mathrm{~cm}$ since no $\mathrm{W}^{+}$line has been observed for $\mathrm{z} \geq 2 \mathrm{~cm}$ in emission 
213 spectra obtained in the visible range (not presented here), aiming in a direction parallel 214 to the cathode. Therefore, the cooling of $\mathrm{T}_{\mathrm{e}}$ when $\mathrm{z}>4 \mathrm{~cm}$ is attributed to $\mathrm{W}$ excitation 215 collisions with electrons. In particular for $\mathrm{z}>4 \mathrm{~cm}$, the plasma light emission decreases 216 strongly. Only $\mathrm{W}$ atomic lines were found in this region (no Ar lines) and the plasma 217 emission was almost non-existent for $\mathrm{z}>6 \mathrm{~cm}$.

218 At low operating pressure, some modelling results confirmed experimentally have 219 shown that when the plasma potential becomes positive after the pre-sheath, it 220 progressively increases or saturates in the bulk plasma (Rossnagel \& Kaufman 1986; 221 Kondo \& Nambu 1999; Bradley et al. 2001). In MS-GAS used for the production of 222 titanium NPs at a pressure similar to ours, LP measurements have evidenced a progressive 223 increase of $V_{p}$ in the direction perpendicular to the cathode (Kousal et al. 2017). In 224 our conditions, a sharp increase of $\mathrm{V}_{\mathrm{p}}$ on the edge of the last magnetic arch has been 225 highlighted and maximum values were measured in a rather central band, parallel to the 226 cathode. The potential energy that a negatively charged NP can have in such a plasma 227 potential distribution shows the presence of a potential well. NPs could have a stable 228 position in this region.

\section{7. Conclusion}

230 Two-dimensional spatial distributions of plasma parameters were established in 231 unbalanced magnetron discharges using a LP. The cathode material was tungsten and 232 argon was used at a pressure of 0.3 mbar in order to produce NPs from cathode sputtering. 233 The magnetic field lines and strength were also established without plasma, using a Hall 234 probe. Despite the presence of NPs of $\sim 20 \mathrm{~nm}$ in size on average, correlations were 235 established between the magnetic field geometry and strength, and the spatial distributions 236 of the electron density and temperature. These correlations are quite similar to those 237 established in magnetron discharges operating at low pressure for material deposition 238 processes. Differences were found in the plasma potential variations from the cathode 239 pre-sheath region where the potential is negative towards the anode plate region. In 240 particular, a sharp potential increase was evidenced on the edge of the last magnetic arch 241 and the maximum values were found in a layer parallel to the electrodes. This particular 242 distribution is at the origin of a NP potential well which was evidenced from the potential 243 energy that an isolated NP of negative charge can reach. Subsequent experiments will be 244 dedicated to investigating whether NPs can have a stable position in this region using the 245 laser extinction method and also whether they could grow there by $\mathrm{W}$ deposition.

\section{Acknowledgements}

This work has been carried out within the framework of the French Federation for Magnetic Fusion Studies (FR-FCM) and the Eurofusion consortium, and has received funding from the Euratom research and training programme 2014-2018 and 2019-2020 under grant agreement no. 633053. The views and opinions expressed herein do not necessarily reflect those of the European Commission.

Editor Edward Thomas thanks the referees for their advice in evaluating this article.

Declaration of interests

The authors report no conflict of interest.

\section{REFERENCES}

Arnas, C., Chami, A., Couedel, L., Acsente, T., CABIE, M. \& Neisius, T. 2019 Thermal balance of tungsten monocrystalline nanoparticles in high pressure magnetron discharges. Phys. Plasmas 26, 053706.

Bernstein, I. B. \& RABINOwitz, I. N. 1959 Theory of electrostatic probes in low-density plasma. Phys. Fluids 2, 112-121. Bogaerts, A., Kolev, I. \& BuYle, G. 2008 Modeling of the magnetron discharge. In Reactive Sputter Deposition (ed. D. Depla \& S. Mahieu). Springer Series in Material Science, vol. 109, pp. 61-130.

Bradley, J. W., Thompson, S. \& Aranda GonZalvo, Y. 2001 Measurements of the plasma potential in a magnetron discharge and the prediction of the electron drift speeds. Plasma Sources Sci. Technol. 10, 490-501. 
Caillard, A., Cuynet, S., Lecas, T., Andreazza, P., Mikikian, M., Thomann, A.-L. \& Brault, P. 2015 PdPt catalyst synthesized using a gas aggregation source and magnetron sputtering for fuel cell electrodes. J. Phys. D: Appl. Phys. 48, 475302.

ChAUdURI, R. G. \& PARIA, S. 2012 Core/shell nanoparticles: classes, properties, synthesis mechanisms, characterization, and applications. Chem. Rev. 112, 2373-2433.

Couedel, L., Mikikian, M., Samarian, A. A. \& Boufendi, L. 2010 Self-excited void instability during dust particle growth in a dusty plasma. Phys. Plasmas 17, 083705 .

CuENYA, R. C. 2010 Synthesis and catalytic properties of metal nanoparticles: size, shape, support, composition, and oxidation state effects. Thin Solid Films 518, 3127-3150.

DePla, D. \& LeRoy, W. P. 2012 Magnetron sputter deposition as visualized by Monte Carlo modeling. Thin Solid Films 520, 6337-6354.

FIELD, D. J., DEw, S. K. \& BuRRell, R. E. 2002 Spatial survey of a magnetron plasma sputtering system using a Langmuir probe. J. Vac. Sci. Technol. A 20, 2032-2041.

Grieve, K., Mulvaney, P. \& Grieser, F. 2000 Synthesis and electronic properties of semiconductor nanoparticles/quantum dots. Curr. Opin. Colloid Interface Sci. 5, 168-172.

Hartmann, H., Popok, V. N., Barke, I., Von Oeynhausen, V. \& Meiwes-Broer, K.-H. 2012 Design and capabilities of an experimental setup based on magnetron sputtering for formation and deposition of size-selected metal clusters on ultra-clean surfaces. Rev. Sci. Instrum. 83, 073304.

HopwOOD, J. \& QIAN, F. 1995 Mechanisms for highly ionized magnetron sputtering. J. Appl. Phys. 78, 758-765.

Kashtanov, P. V., Sirnov, B. M. \& HiPPleR, R. 2007 Magnetron plasma and nanotechnology. Phys.-Uspekhi 50, 455-488.

Kelly, K. L., Coronado, E., Zaho, L. L. \& Schatz, G. C. 2003 The optical properties of metal nanoparticles: the influence of size, shape, and dielectric environment. J. Phys. Chem. B 107, 668-677.

Kishor Kumar, K., Couedel, L. \& Arnas, C. 2014 Nanoparticles in direct current discharges: growth and electrostatic coupling. J. Plasma Phys. 80, 849-853.

Kolpakova, A., KudRnA, P. \& Tichy, M. 2013 Langmuir probe diagnostics of DC cylindrical magnetron. In WDS' 13 Proceedings of Contributed Papers, Part II, pp. 127-133.

Kondo, S. \& NAMBU, K. 1999 A self-consistent numerical analysis of a planar DC magnetron discharge by particle -incell/Monte Carlo method. J. Phys. D: Appl. Phys. 32, 1142-1152.

Koten, M. A., Voeller, S. A., Patterson, M. M. \& Shield, J. E. 2016 In situ measurements of plasma properties during gas-condensation of $\mathrm{Cu}$ nanoparticles. J. Appl. Phys 119, 114306. Kousal, J., KolPaKova, A., Shelemin, A., KudRnA, P., Tichy, M., KYLIAN, O., HANUS, J.,

Choukourov, A. \& Biederman, H. 2017 Monitoring of conditions inside gas aggregation cluster source during production of $\mathrm{Ti} / \mathrm{TiO}_{\mathrm{x}}$ nanoparticles. Plasma Sources Sci. Technol. 26, 1005003.

Michau, A., Hassouni, K. \& Arnas, C. 2017 Aerosol dynamics in a sputtering discharge. J. Appl. Phys. 121, 163301.

Ouaras, K., Hassouni, K., Colina Delacqua, L., Lombardi, G., VRel, D. \& Bonin, X. 2015 Tungsten dust nanoparticles generation from blistering bursts under hydrogen environment in microwave ECR discharge. J. Nucl. Mater. 466, 65-68.

Palmero, A., Van Hattum, E. D., Arnoldbik, W. M., Vredenberg, A. M. \& Habraken, P. M. 2004 Characterization of the plasma in radio-frequency magnetron sputtering system. J. Appl. Phys. 95, 7611.

Rojo, M., Glad, X., Margot, J., Dap, S. \& ClergerauX, R. 2019 Charging and heating processes of dust particles in an electron cyclotron resonance plasma. Plasma Sources Sci. Technol. 28, 085004. RossnAGEL, S. M. \& KAUfMAN, H. R. 1986 Langmuir probe characterization of magnetron operation.

J. Vac. Sci. Technol. A 4, 1822-1825.

Sigurjonsson, P., Larsson, P., Lundin, D., Helmersson, U. \& Gudmundsson, J. T. 2009

Langmuir probe study of the plasma parameters in the HiPIMS discharge. In 52nd Annual Technical

Conference Proceedings, Santa Clara, CA, ISSN 0737-5921.

Wei, X., Skomski, R., Balamurugan, B., Sun, Z. G., Ducharma, S. \& Sellmyr, D. J. 2009

Magnetism of TiO and TiO2 nanoclusters. J. Appl. Phys. 105, $07 \mathrm{C} 517$. 